\title{
Health System Factors Influencing Practice of Neonatal Resuscitation among Nurses in Machakos Level 5 Hospital
}

\author{
Daniel MM ${ }^{1 *}$, Joseph $\mathrm{T}^{2}$ and Kenneth $\mathbf{R}^{3}$ \\ ${ }^{1}$ Department of Reproductive health, Kenyatta University, Kenya \\ 2Department of Obstetrics and Gynecology, Kenyatta University, Kenya \\ ${ }^{3}$ Department of Health Management and Informatics, Kenyatta University, Kenya
}

*Corresponding author: Musyoki Daniel Muli, Department of Reproductive health,

\section{Research Article \\ Volume 3 Issue 2}

Received Date: October 06, 2019

Published Date: November 04, 2019

DOI: $10.23880 /$ phoa- 16000147

Kenyatta University, Kenya, Email: borayajoshua@gmail.com

\section{Abstract}

The first minute after birth is usually referred to as the golden minute, and the new born baby should be able to initiate spontaneous breathing, failure to which a condition called birth asphyxia ensues. Globally, approximately 5 per cent to10 per cent of newborns in facilities require resuscitation after delivery. In sub-Saharan Africa where over one third of all intrapartum related neonatal deaths occur, the rates of skilled attendance at birth are very low. In Kenya neonatal mortality remains at 22/100,000 live births, majority associated with poor resuscitation. This study sought to assess neonatal resuscitation practice among nurses in Machakos Level 5 Hospital, in Machakos County, Kenya. Specifically the study sought to assess health system factors that influence practice of neonatal resuscitation among nurses. The study adopted a descriptive cross-sectional study design. The study population included a sample of 201 nurses working in Machakos level 5 hospitals in Machakos County. Quantitative data was collected using semi-structured questionnaires from selected nurses through systematic random sampling at a predetermined interval of 2 . Qualitative data was collected using key informant interview schedules with 6 selected Key Informants. Key informants were purposively selected for inclusion in the study. Descriptive statistics were analyzed using Statistical Package for Social Sciences (spss) version 24.0 with the aid of Microsoft Excel program to generate frequency tables, graphs and pie-charts. Qualitative data was analyzed using thematic analysis and results triangulated with quantitative data as narrations. To test the association between study variables, Chi-Square tests done was at 95\% confidence interval $(\mathrm{p}<0.05)$ were used. The study results revealed that 41 per cent of respondents fully practiced neonatal resuscitation. Health system factors that significantly influenced neonatal resuscitation included; availability of resuscitation equipment (p=0.001), place of keeping resuscitation equipment $(\mathrm{p}=0.021)$ and reference to guidelines $(\mathrm{p}=0.001)$. The study recommends increased rates of continuous medical education of nurses coupled with strict supervision to increase achievement rates of practicing neonatal resuscitation according to the guidelines. The Ministry of Health and Machakos County should create awareness 
to the policy makers on training methods to improve on the level of skill and knowledge on newborn resuscitation among nurses deployed in the country's medical institutions thus reducing rates of neonatal mortality.

Keywords: Neonatal Resuscitation; Resuscitation Factors; Asphyxia

\section{Background of the study}

The birth of a newborn is one of the happiest moments for the parents. The process of birth takes several hours, but the most crucial moments for the newborn child is usually the first few hours of life, with the risk of dying decreasing as the child grows. Statistics indicate that by 2011, there were three million recorded neonatal deaths worldwide, and most of these were recorded in low income countries. Of allthesedeaths $23 \%$ are attributed to intrapartum related hypoxic events formerly referred to as asphyxia [1]. Approximately 5\%to10\% of newborns in facilities will require resuscitation, which includes stimulation at birth and assisted ventilation with bag and mask to help them breath. This procedure has proven to reduce intrapartum related neonatal deaths by30\% [2].

The first minute after birth this usually referred to as the golden minute, and the baby should be able to initiate spontaneous breathing, failure to which birth asphyxia ensues. Every newborn should be considered at a high risk of birth asphyxia since most cases of asphyxia are difficult to be predicted [3]. Birth asphyxia is linked to increased neonatal morbidity and mortality especially in low-income settings [4]. Training on newborn resuscitation by health workers plays a major role in the practice of newborn resuscitation as early diagnosis and prompt interventions help to reduce adverse consequences associated with birth asphyxia.

The success of newborn resuscitation is dependent on the knowledge and skill of the birth attendant, as well as the access to basic equipment including towels and blankets for drying, a bag and mask resuscitator and suction device. Several systematic reviews report that short interactive in-service training using a combination of didactic and emulation-based teaching methods results in sustained improvement of knowledge, skills, teamwork, and confidence of healthcare providers [3]. The burden of intrapartum events is greatest in low income setting. In sub-Saharan Africa and south East Asia where over one third of all intrapartum related death occurs, the rate of skilled attendance at birth is very low. Hospital deliveries in these regions have staffs that are not frequently trained in resuscitation, and equipment is no available [5].

All healthcare institutions conducting deliveries should be equipped with basic equipment to conduct both basic and advanced neonatal resuscitation. The World Health Organization has listed the following equipment and tools as a prerequisite for effective resuscitation of the newborns; radiant warmer, warm blankets, suction, instruments for intravenous access, trays equipped with emergency procedure tools, and drugs that may be used in cases of advanced resuscitation. Lack of the above mentioned equipment could lead to improvising and then deviations from WHO resuscitation guidelines and therefore poor outcomes in health on newborns [6].

In Afghanistan supportive supervision and continuous professional development which is purely health system factor is poorly underutilized. The findings further noted that due to lack of continuous learning the performance of resuscitation and confidence of workers improved significantly after competency based debriefing session on resuscitation was organized by the hospital management to the workers [7].

A study done in Rwanda found the health system characteristics such as health equipment, adequate staffing and continuous training of health workers was significantly associated with their performance in newborn resuscitation [8]. Health system factors have been studied and evidence been presented to justify that the health system itself influences newborn resuscitation that healthcare workers provide to newborns. In a study done in Ethiopia missing equipment for resuscitation was cited by the healthcare workers interviewed as one of the reasons that they could not effectively resuscitate newborns in the hospitals [9]. Availability of equipment's for newborn resuscitation is key and the United nations commission on life saving commodities for women and children includes a bag, valve mask device in the list of thirteen affordable and effective life saving equipment's that are underutilized in poor and low income countries [10]. In another study done to assess the health system capacity to conduct newborn resuscitation found 
majority of health centers in Ethiopia lack mucus extractor's ambu-bags and guidelines [9].

In Kenya, Shikuku, et al. conducted a study to establish the quality of neonatal care during neonatal resuscitation in public hospitals [11]. The findings revealed that all the basic equipment's for newborn resuscitation were all available meaning that hospitals were adequately prepared but still the healthcare workers missed on the key steps followed in newborn resuscitation. Kenya has a high neonatal mortality rate of 22 per 1000 live births. The Demographic Health Survey statistics in Machakos level 5 hospitals, Machakos County reveal a high number of neonatal deaths recorded in the last two years. The year 2014/2015 recorded 213 neonatal deaths and 2015/2016-256 neonatal deaths. In Kenya, inadequate training among the healthcare providers remains a barrier towards newborn resuscitation [4]. Research has been limited on healthcare providers' actual performance on newborn resuscitation procedures and on individual or facility level characteristics associated with performance. These studies have taken into concern the concept of newborn resuscitation but in a broader perspective, they do not in the long run impact on newborn resuscitation training or on the practices of nurses in specific regions in Kenya. Evaluation has been at the level of the healthcare providers, very few studies have evaluated the impact of training on change in practice of neonatal resuscitation

\section{Methodology}

The study used a descriptive cross-sectional survey design to collect and analyze both quantitative and qualitative data. The study was carried out in Machakos level 5 hospitals in Machakos County. The study involved nurses working in maternity, paediatric unit, and newborn unit. The hospital was purposively chosen since they offer newborn resuscitation services and has high neonatal mortality. Respondents were selected using systematic random sampling at a sampling interval of 2 after calculating the $\mathrm{K}^{\text {th }}$ value until a sample of 201 nurses [12]. The number of respondents selected from each unit/department was proportional to the number of nurses in each study site. The questionnaire was divided into two sections; A and B. Section A captured the basic information of the respondents, such as occupation, level of education and working experience. Section B captured information relating health system and knowledge factors. The checklist had statements to capture information on monitoring the practice of neonatal resuscitation among respondents. Qualitative data was collected using Key informant guide involving nursing officer in-charge of newborn unit, pediatric unit, maternity unit, $\mathrm{MCH}$ unit, health administrative officer and medical superintendent.

Pretesting of research tools ensured clarity of questions to respondents thus eliciting the required information. The researcher also incorporated expert opinions (supervisors) to construct well-structured research instruments. Reliability was established using the test-retest technique. First, test-retest reliability was obtained through administering the same research instruments twice over a given period of time to a group of selected household heads. The scores from Time 1 and Time 2 were then compared so as to evaluate the stability of the results over time. This enabled checking on the accuracy of the instruments so as to achieve true and accurate answers. Secondly, inter-rater reliability was employed to ascertain the extent to which different individuals agreed in assessing their decisions. They were asked similar questions and gave a variety of answers which were correlated. Inter-rater reliability was helpful since human subjects interpreted assessed questions differently. Different raters may disagree on certain answers or materials that show knowledge of the skill or construct under assessment.

Data collection was done across a period of six months from September 2018 to February 2019. The respondents were guided to fill their responses by the trained research assistants. The researcher sought approval from Kenyatta University Graduate School. Ethical clearance to carry out this research was obtained from Kenyatta University Ethics Review Committee (KUERC). The researcher first sought the necessary authorization for research from Kenyatta University graduate school, from NACOSTI and from

Machakos level 5 hospital chief officers. The researcher then moved to various unitswithinthelevel5hospitalto collect data. The researcher together with research assistants administered questionnaires to nurses working in Machakos level 5 hospital units; MCH units, Paedriatics units, newborn units and maternity units to collect quantitative data. An informed consent to participate in the study was gotten from each respondent. Study respondents were assured of privacy and confidentiality of information given. They were treated with the respect they deserved and participation in the study was voluntary without due coercion.

Quantitative data from questionnaires were cleaned, coded, double entered, double checked and stored into 
Microsoft Excel program for analysis. Data was then exported to SPSS version 22.0 for analysis. Descriptive statistics were presented as charts, graphs, percentages and frequency distribution tables. Inferential statistics were used to test the association between the study variables. This was achieved through Chi-square and Fisher's Exact Tests done at 95\% confidence interval and p-values less than 0.05 considered significant. Qualitative data from KII were triangulated with quantitative data as direct quotes or narrations presented in verbatim.

\section{Results}

\section{Demographic Characteristics of the Participants}

There were a total of 201 respondents which was $100 \%$.The results showed that the respondents were at least 20 years of age. More than a third 79 (39.3\%) of the respondents were aged between 40-49 years followed by 57 (28.4\%) who were aged between 30-39 years. Regarding the respondents' years in current position, more than half $109(54.2 \%)$ of the respondents had been in their current position between 0-3 years followed by
$47(23.4 \%)$ who had been in their current position between 4-5 years 243 (61.2\%). More than half 117 $(58.2 \%)$ of the respondents were female while 84 $(41.8 \%)$ of them were male.

Regarding the respondents' highest level of education attained, the results revealed that more than half 106 $(52.7 \%)$ of the respondents had a registered nurse (Diploma) followed by 53 (26.4\%) registered nurse (Degree). The findings showed that slightly more than half $101(50.2 \%)$ of the respondents had been trained on neonatal resuscitation while $100(49.8 \%)$ of them had not been trained. Among the respondents who had been trained on neonatal resuscitation, more than half 55 $(54.5 \%)$ of them reported to have been trained in a duration of between 1-2 years followed by 27 (26.7\%) who had been trained in a year or less. When the respondents were asked on the number of times, they had performed neonatal resuscitation, majority 133 (66.2\%) of them revealed that they had performed it less than 5 times followed by $49(24.4 \%)$ who had performed it between 5-10 times. The results were as shown in Table 1.

\begin{tabular}{|c|c|c|c|}
\hline Variable & Respondent response & Frequency (N) & Percentage (\%) \\
\hline \multirow{4}{*}{ Age } & $20-29$ & 40 & 19.9 \\
\hline & $30-39$ & 57 & 28.4 \\
\hline & $40-49$ & 79 & 39.3 \\
\hline & Over 50 & 25 & 12.4 \\
\hline \multirow{4}{*}{ Years in current position } & $<3$ & 109 & 54.2 \\
\hline & 5-Apr & 47 & 23.4 \\
\hline & 10-Jun & 15 & 7.5 \\
\hline & Over 10 & 30 & 14.9 \\
\hline \multirow{2}{*}{ Gender } & Male & 84 & 41.8 \\
\hline & Female & 117 & 58.2 \\
\hline \multirow{4}{*}{ Highest level of education } & Enrolled nurse (Certificate) & 31 & 15.4 \\
\hline & Registered nurse (Diploma) & 106 & 52.7 \\
\hline & Registered nurse (Degree) & 53 & 26.4 \\
\hline & Registered nurse (Masters) & 11 & 5.5 \\
\hline \multirow{2}{*}{$\begin{array}{l}\text { Trained on neonatal } \\
\text { resuscitation }\end{array}$} & Yes & 101 & 50.2 \\
\hline & No & 100 & 49.8 \\
\hline \multirow{2}{*}{ Type of training } & EMONC & 77 & 76.2 \\
\hline & ETAT+ & 24 & 23.8 \\
\hline \multirow{3}{*}{$\begin{array}{c}\text { Duration of training from last } \\
\text { one }\end{array}$} & $<1$ Year & 27 & 26.7 \\
\hline & 1-2 Years & 55 & 54.5 \\
\hline & $>3$ Years & 19 & 18.8 \\
\hline \multirow{3}{*}{$\begin{array}{l}\text { Number of times you } \\
\text { performed new born } \\
\text { resuscitation }\end{array}$} & $<5$ Times & 133 & 66.2 \\
\hline & 5-10 Times & 49 & 24.4 \\
\hline & $>10$ Times & 19 & 9.5 \\
\hline
\end{tabular}

Table 1: Distribution of individual factors among respondents $(n=201)$. 


\section{Health System Factors}

Concerning the availability of resuscitation equipment, the research findings revealed that majority 135 (67\%) of the respondents reported that the equipment was available to them while the rest $66(33 \%)$ of them said that the equipment were not available. Regarding the influence of the resuscitation equipment on neonatal care, majority $145(72 \%)$ of the respondents revealed that the equipment influenced neonatal care while the rest 56 (28\%) did not see any influence. Majority 147 (73.1\%) of the respondents reported that they kept the neonatal equipment at the resuscitation tray followed by 40 $(19.9 \%)$ of them kept the equipment in the locked cupboard. Regarding whether the respondents referred to resuscitation guidelines, the results revealed that below half $86(42.8 \%)$ of the respondents sometimes referred followed by $55(27.4 \%)$ who referred to the guidelines all the time. When the respondents were queried on what motivated them to use the guidelines, slightly below half $96(47.8 \%)$ of the respondents revealed that they were motivated by the fact that the guidelines were on the wall followed by 39 (19.4\%) who said they were motivated by the need to save lives.

The results sought to know the hindrances to using resuscitation guidelines. The results revealed that more than a third 78 (38.8\%) of the respondents revealed that lack of supervision was their hindrance to using the guidelines followed by 59 (29.4\%) who said they lacked the knowledge on resuscitation guidelines. Concerning the presence of team leader within the hospital, the results revealed that majority $154 \quad(77 \%)$ of the respondents revealed there was no team leader while the rest $47(23 \%)$ of them said there was a resuscitation team leader in the hospital. Among those who revealed that there was presence of a team leader at the hospital, the results further revealed that more than half 23 (55\%) of the respondents said the team leader was available during resuscitation while the rest 19 (45\%) said the team leader wasn't available during the exercise (Table 2).

\begin{tabular}{|c|c|c|c|}
\hline Variable & Category & Frequency (N) & Percentage (\%) \\
\hline \multirow{2}{*}{ Availability of resuscitation equipment } & Yes & 135 & 67 \\
\hline & No & 66 & 33 \\
\hline \multirow{2}{*}{$\begin{array}{l}\text { Resuscitation equipment influences } \\
\text { neonatal care }\end{array}$} & Yes & 145 & 72 \\
\hline & No & 56 & 28 \\
\hline \multirow{3}{*}{ Where the resuscitation equipment kept } & Locked cupboards & 40 & 19.9 \\
\hline & Resuscitation tray & 147 & 73.1 \\
\hline & Equipment store & 14 & 7 \\
\hline \multirow{4}{*}{$\begin{array}{l}\text { Use of resuscitation guidelines or } \\
\text { referring to guidelines on resuscitation }\end{array}$} & All the times & 55 & 27.4 \\
\hline & Not at all & 22 & 10.9 \\
\hline & Sometimes & 86 & 42.8 \\
\hline & Rarely & 38 & 18.9 \\
\hline \multirow{4}{*}{$\begin{array}{l}\text { What motivates the nurse to use } \\
\text { guidelines }\end{array}$} & Guidelines on the wall & 96 & 47.8 \\
\hline & Presence of supervisor & 34 & 16.9 \\
\hline & Simplicity of guidelines & 32 & 15.9 \\
\hline & Need to save lives & 39 & 19.4 \\
\hline \multirow{4}{*}{$\begin{array}{l}\text { Hindrances for using resuscitation } \\
\text { guidelines }\end{array}$} & Lack of orientation & 37 & 18.4 \\
\hline & Lack of knowledge & 59 & 29.4 \\
\hline & Lack of commitment & 27 & 13.4 \\
\hline & Lack of supervision & 78 & 38.8 \\
\hline \multirow{2}{*}{$\begin{array}{l}\text { Availability of team leader during } \\
\text { resuscitation }\end{array}$} & Yes & 47 & 23 \\
\hline & No & 154 & 77 \\
\hline
\end{tabular}

Table 2: Summary of health facility factors affecting resuscitation.

\section{Influence of health System Factors on Practice of Neonatal Resuscitation}

The researcher sought to determine the influence of health system factors on the practice of neonatal resuscitation. The results showed that majority 61
$(74.4 \%)$ of the respondents who said that the resuscitation equipment was available fully practiced neonatal resuscitation. There was a significant statistical association between availability of resuscitation equipment and practice of neonatal resuscitation 
$(\mathrm{p}=0.001)$. The research findings revealed that majority $57(69.5 \%)$ of the respondents who reported that resuscitation equipment influenced care given to neonates fully practiced neonatal resuscitation. There was a statistical association between resuscitation equipment influences care given to neonates and practice of fully neonatal resuscitation $(p=0.032)$. One of the medical superintendents who was in a Key Informant Interview session reported;

"...this is the biggest referral hospital in Machakos County which serves clients from other counties as well. So sometimes the equipment available may not be enough for the rising demand in the hospital. However, we have tried to purchase the equipment and amend the faulty ones. It's also good to note that even with the few we have still if used well we can be able to save lives through adequate commitment to fully resuscitation practice ..."

\section{Respondent 1}

Concerning place of keeping resuscitation equipment, results showed that majority $50 \quad(61.0 \%)$ of the respondents who kept them at the resuscitation tray fully practiced neonatal resuscitation. There was a significant statistical association between place of keeping the resuscitation equipment and fully practiced neonatal resuscitation $(\mathrm{p}=0.021)$. The findings revealed that more than a third $34(41.4 \%)$ of the respondents who sometimes referred to the guidelines during neonatal resuscitation fully practiced neonatal resuscitation. There was an association between reference to guidelines during neonatal resuscitation and practice of neonatal resuscitation $(\mathrm{p}=0.001)$.

Regarding to motivation for use of resuscitation guidelines, the results that slightly more than half 61 $(51.2 \%)$ of the respondents who were motivated by the guidelines being on the partially practiced neonatal resuscitation. There was no significant statistical association between motivation to use the neonatal resuscitation guidelines and practice of neonatal resuscitation ( $\mathrm{p}=0.471)$. With regards to hindrance to use of neonatal guidelines, slightly below half $39(47.7 \%)$ of the respondents who reported lack of supervision was the major hindrance fully practiced neonatal resuscitation. However, there was no association between hindrance to use of neonatal and practice of neonatal resuscitation $(p=0.070)$. One of the Nurses in maternity unit in a Key Informant Interview session reported;

“...Few of our nurses do not follow the neonatal resuscitation guidelines even when they are displayed in the walls. This has been indeed one of the challenges facing us in this facility. Other challenges which affect fully practice of neonatal resuscitation includes: lack of adequate training by the nurses, workload, negative attitude by the nurses among others. ..."

\section{Respondent 2}

The results revealed that majority $60(73.2 \%)$ of the respondents who reported that there was no neonatal resuscitation team leader in the hospital fully practiced neonatal resuscitation. There was no statistical association between presence of a team leader at the hospital and practice of neonatal resuscitation $(\mathrm{p}=0.338)$. Among the respondents who reported that there was a team leader at the hospital, majority $15(60.0 \%)$ who revealed that the team leader was available during neonatal resuscitation exercise partially practiced neonatal resuscitation. There was however no significant statistical association between availability of the team leader during neonatal resuscitation and practice of neonatal resuscitation $(p=0.408)$. The results were as presented in the Table 3 below:

\begin{tabular}{|c|c|c|c|c|}
\hline \multirow{3}{*}{ Independent variable } & \multirow{3}{*}{ Respondent response } & \multicolumn{2}{|c|}{$\begin{array}{c}\text { Dependent variable (Practice of } \\
\text { neonatal resuscitation) }\end{array}$} & \multirow{3}{*}{$\begin{array}{l}\text { Statistical } \\
\text { significance }\end{array}$} \\
\hline & & Full practice & Partial practice & \\
\hline & & $(\mathrm{N}=82)$ & $(\mathrm{N}=119)$ & \\
\hline \multirow{3}{*}{$\begin{array}{c}\text { Availability of resuscitation } \\
\text { equipment }\end{array}$} & \multirow{2}{*}{ Yes } & \multirow{2}{*}{$61(74.4 \%)$} & \multirow{2}{*}{$74(62.2 \%)$} & $\chi^{2}=44.900$ \\
\hline & & & & $\mathrm{df}=1$ \\
\hline & No & $21(25.6 \%)$ & $45(37.8 \%)$ & $\mathrm{p}=0.001$ \\
\hline \multirow{3}{*}{$\begin{array}{l}\text { Resuscitation equipment influences } \\
\text { care given to neonates }\end{array}$} & \multirow{2}{*}{ Yes } & \multirow{2}{*}{$57(69.5 \%)$} & \multirow{2}{*}{$88(73.9 \%)$} & $\chi^{2}=32.639$ \\
\hline & & & & $\mathrm{df}=1$ \\
\hline & No & $25(30.5 \%)$ & $31(26.1 \%)$ & $\mathrm{p}=0.032$ \\
\hline \multirow{3}{*}{$\begin{array}{c}\text { Place of keeping resuscitation } \\
\text { equipment }\end{array}$} & Locked cupboard & $27(32.9 \%)$ & $13(10.9 \%)$ & $\chi^{2}=14.759$ \\
\hline & Resuscitation tray & $50(61.0 \%)$ & $97(81.5 \%)$ & $\mathrm{df}=2$ \\
\hline & Equipment store & $5(6.1 \%)$ & $9(7.6 \%)$ & $\mathrm{p}=0.021$ \\
\hline
\end{tabular}




\begin{tabular}{|c|c|c|c|c|}
\hline \multirow{4}{*}{$\begin{array}{l}\text { Reference to guidelines during } \\
\text { neonatal resuscitation }\end{array}$} & All times & $25(30.5 \%)$ & $30(25.2 \%)$ & $\chi^{2}=25.210$ \\
\hline & Not at all & $9(11.0 \%)$ & $13(10.9 \%)$ & $\mathrm{df}=3$ \\
\hline & Sometimes & $34(41.4 \%)$ & $52(43.7 \%)$ & $\mathrm{p}=0.001$ \\
\hline & Rarely & $14(17.1 \%)$ & $24(20.2 \%)$ & \\
\hline \multirow{4}{*}{$\begin{array}{l}\text { Motivation for use of resuscitation } \\
\text { guidelines }\end{array}$} & Guidelines on the wall & $35(42.7 \%)$ & $61(51.2 \%)$ & $\chi^{2}=2.526$ \\
\hline & Supervisor presence & $14(17.1 \%)$ & $20(16.8 \%)$ & $\mathrm{df}=3$ \\
\hline & Simplicity of guidelines & $13(15.9 \%)$ & $19(16.0 \%)$ & $\mathrm{p}=0.471$ \\
\hline & Need to save lives & $20(24.3 \%)$ & $19(16.0 \%)$ & \\
\hline \multirow{4}{*}{$\begin{array}{l}\text { Hindrances for using neonatal } \\
\text { guidelines }\end{array}$} & Lack of orientation & $9(11.0 \%)$ & $28(23.5 \%)$ & $\chi^{2}=7.050$ \\
\hline & Lack of knowledge & $24(29.2 \%)$ & $35(29.4 \%)$ & $\mathrm{df}=3$ \\
\hline & Lack of commitment & $10(12.2 \%)$ & $17(14.3 \%)$ & $\mathrm{p}=0.070$ \\
\hline & Lack of supervision & $39(47.7 \%)$ & $39(32.8 \%)$ & \\
\hline \multirow{2}{*}{ Presence of team leader } & Yes & $22(26.8 \%)$ & $25(21.0 \%)$ & $\begin{array}{c}\chi^{2}=0.918 \\
\mathrm{df}=1\end{array}$ \\
\hline & No & $60(73.2 \%)$ & $94(79.0 \%)$ & $\mathrm{p}=0.338$ \\
\hline \multirow{2}{*}{ Availability of team leader } & Yes & $8(47.1 \%)$ & $15(60.0 \%)$ & $\begin{array}{c}\chi^{2}=0.684 \\
\mathrm{df}=1\end{array}$ \\
\hline & No & $9(52.9 \%)$ & $10(40.0 \%)$ & $\mathrm{p}=0.408$ \\
\hline
\end{tabular}

Table 3: Association between health system factors and practice of neonatal resuscitation among respondents $(\mathrm{n}=201)$.

\section{Discussion}

Concerning the availability of resuscitation equipment, the research findings revealed that majority of the respondents reported that the equipment were available when required. This meant they were easily accessible to assist in quick neonatal resuscitation process initiation whenever deemed necessary to ensure child survival. This explains the existence of a significant statistical association between availability of resuscitation equipment and practice of neonatal resuscitation. All health care institutions conducting deliveries should be equipped with basic equipment to conduct both basic and advanced neonatal resuscitation. The results were contrary to a report by World Health Organization which attributed lack of neonatal resuscitation equipment leading to improvising thus ensure the procedure is initiated as early as it is required. This may further lead to deviations in the WHO resuscitation guidelines and therefore poor outcomes in the health of newborns [6]. In a study done in Ethiopia missing equipment for resuscitation was cited by the health care workers interviewed as one of the reasons that they could not effectively resuscitate newborns in the hospitals during delivery [9]. Similar results were reported in another study done in Kenya to establish the quality of neonatal care during neonatal resuscitation in public hospitals. The findings revealed availability of all the basic equipment for newborn resuscitation meaning hospitals were adequately prepared but still healthcare workers missed on key steps followed while conducting newborn resuscitation [11]. Majority of the respondents reported that resuscitation equipment was kept in resuscitation trays for easy access. This explains the existence of a significant influence of where the equipment was kept and practice of neonatal resuscitation. The results were in agreement with a health assessment study done in Ghana which revealed that resuscitation equipment were kept in places where they were easily accessible to ensure effective and efficient resuscitation procedures [13,14]. Similar results were reported by a study done by Yoxall, et al. on providing newborn resuscitation revealed that resuscitation equipment were kept in mobile trolley for easy usability and accessibility.

Regarding whether the respondents referred to resuscitation guidelines, the results revealed that most of the respondents referred to them sometimes. This is because resuscitation guidelines give the correct standard operating procedures for conducting the practice. This serves as a reference tool that reminds care providers the necessary steps required in conducting effective neonatal resuscitation. In fact, those who mostly referred to neonatal guidelines were at a better position to fully practice neonatal resuscitation. The results were inconsistent with a study done among healthcare workers in district hospitals in Papua New Ginea, Oceania in which the results revealed that practitioners rarely refer to neonatal resuscitation guidelines [15]. Similar results were reported in which nurses after a six months training were reported to follow and refer to neonatal resuscitation as a motivation after being trained [16]. 
Training motivates care providers to use resuscitation guidelines. With regards to hindrances to using resuscitation guidelines, the results revealed that more majority of respondents reported that lack of supervision was their main hindrance to using the guidelines. This means that when proper supervision is lacked, the care providers don't see the necessary need to engage in making references to use the resuscitation guidelines as well as them being unavailable. The results were contrary to a study done by Surcouf, et al. in which heavy workload and lack of time was the main hindrance to using resuscitation guidelines while conducting such processes. Lack of adequate personnel means a supervision challenge as reported by a study done by was a significant barrier to using resuscitation guidelines among care givers $[17,18]$.

Regarding availability of team leader while conducting neonatal resuscitation in the hospital, the results revealed that majority of the respondents revealed there was no team leader. This meant that most of the resuscitation procedures were done either individually. This can be attributed to heavy workloads in public hospitals as a result of many deliveries occurring due to free maternal delivery program. The presence of a team leader helps in coordinating the other team members during resuscitation hence positive outcomes [19]. However, there was no significant statistical association between availability of a team leader and practice of neonatal resuscitation. This may be attributed to the fact that presence of a team leader may lead to hesitancy in sharing information among those conducting neonatal resuscitation [20-22].

\section{Conclusion}

The results further revealed that health system factors significant affected practice of neonatal resuscitation. With this regard, availability of resuscitation equipment, place of keeping resuscitation equipment and reference to resuscitation guidelines influenced practice of resuscitation among respondents. This means that health system factors determine the outcome neonatal resuscitation.

\section{Recommendation}

The ministry of health, county government and hospital administration should ensure that there's availability of a team leader who should provide adequate supervision and adherence to resuscitation guidelines.

\section{Acknowledgement}

My sincere gratitude goes to my supervisors, $\mathrm{Dr}$ Joseph Thigiti and Dr Kenneth Rucha for their generous contributions, positive criticisms, advice and commitment in guiding me through the entire process of developing this thesis. Special appreciation goes to Kenyatta University, School of Public Health and Applied Human Sciences and Department of Population, Reproductive Health and Community Resource Management, especially my lecturers for their maximum cooperation, extra devotion and help to successfully undertake this course. Acknowledgement goes to Machakos Level 5 Hospital Management for the input and cooperation of and study respondents for their willingness to participate in this study. Lastly, the researcher acknowledges the family, friends and relatives for their financial, moral and spiritual support without which this work could not have been a success.

Declaration of interest: None declared.

\section{References}

1. Lawn JE, Lee AC, Kinney M, Sibley L, Carlo WA (2009) Two million Intrapartum-related stillbirths and neonatal deaths: Where, why, and what can be done? International Journal of Gynecology and Obstetrics 107(1): S5-18.

2. Lee AC, Cousens S, Wall SN, Niermeyer S, Darmstadt GL, et al. (2011) Neonatal resuscitation and immediate newborn assessment and stimulation for the prevention of neonatal deaths: A systematic review, meta-analysis and Delphi estimation of mortality effect. BMC Public Health 11(3): S12.

3. Chitkara R, Rajani AK, Oehlert JW, Lee HC, Epi MS, et al. (2013) The accuracy of human senses in the detection of neonatal heart rate during standardized simulated resuscitation: implications for delivery of care, training and technology design. Resuscitation 84(3): 369-372.

4. Murila F, Obimbo MM, Musoke R (2012) Assessment of knowledge on newborn resuscitation amongst health care providers in Kenya. Pan Afr Med J 11: 78.

5. UNICEF (2009) The State of the world's children. Maternal and Newborn health.

6. World Health Organization (2012) Guidelines on Basic Newborn Resuscitation. Geneva: World Health Organization. 
7. Kim Y, Ansari N, Kols A, Tappis H, Currie S, et al. (2013) Assessing the capacity for newborn resuscitation and factors associated with providers' knowledge and skills: a cross-sectional study in Afghanistan. BMC Pediatrics 13: 140.

8. Sipsma HL, Curry LA, Kakoma JB, Linnander EL, Bradley EH (2012) Identifying characteristics associated with performing recommended practices in maternal and newborn care among health facilities in Rwanda: a cross-sectional study. Hum Resour Health 10: 13.

9. Haile-Mariam A, Tesfaye N, Otterness C, Bailey PE (2012) Assessing the health system's capacity to conduct newborn resuscitation in Ethiopia. Ethiop Med J 50(1): 43-55.

10. Coffey P, Kak L, Narayanan I, Lockwood JB, Singhal N (2012) Newborn Resuscitation Devices. Working Paper Prepared for The United Nations Commission on Life-Saving Commodities for Women and Children.

11. Shikuku D, Milimo B, Ayebare E, Gisore P, Nalwadda G (2017) Quality of care during neonatal resuscitation in Kakamega county general hospital, Kenya: A direct observation study. Biomed Research International, pp: 12

12. Kothari CR (2004) Research Methodology: Methods \& Techniques, $2^{\text {nd }}$ [Edn.], New age International Publishers, New Delhi, India.

13. Vesel L, Manu A, Lohela TJ, Gabrysch S, Okyere E (2013) Quality of newborn care: a health facility assessment in rural Ghana using survey, vignette and surveillance data. BMJ open 3(5): 1-11.

14. Yoxall CW, Thomas MR, Weeks AD, Duley L (2014) Providing newborn resuscitation at the mother's bedside: assessing the safety, usability and acceptability of a mobile trolley. BMC pediatrics 14(1): 135.
15. Sa'avu M, Duke T, Matai S (2014) Improving paediatric and neonatal care in rural district hospitals in the highlands of Papua New Guinea: a quality improvement approach. Paediatr Int Child Health 34(2): 75-83.

16. Ashish KC, Wrammert J, Nelin V, Clark RB, Ewald U, et al. (2017) Evaluation of Helping Babies Breathe Quality Improvement Cycle (HBB-QIC) on retention of neonatal resuscitation skills six months after training in Nepal. BMC pediatrics 17(1): 103.

17. Surcouf JW, Chauvin SW, Ferry J, Yang T, Barkemeyer B (2013) Enhancing residents' neonatal resuscitation competency through unannounced simulation-based training. Med Educ Online 18(1): 1-7.

18. Knight LJ, Gabhart JM, Earnest KS, Leong KM, Anglemyer A, et al. (2014) Improving code team performance and survival outcomes: implementation of pediatric resuscitation team training. Crit Care Med 42(2): 243-251.

19. Castelao EF, Russo SG, Riethmüller M, Boos M (2013) Effects of team coordination during cardiopulmonary resuscitation: A systematic review of the literature. J Crit Care 28(4): 504-521.

20. Kessler DO, Cheng A, Mullan PC (2015) Debriefing in the emergency department after clinical events: a practical guide. Ann Emerg Med 65(6): 690-698.

21. Yamane T (1967) Statistics, an Introductory Analysis, $2^{\text {nd }}($ Edn.), Harper and Row, New York.

22. Disu EA, Ferguson IC, Njokanma OF, Anga LA, Solarin AU (2015) National neonatal resuscitation training program in Nigeria (2008-2012): A preliminary report. Nigerian journal of clinical practice 18(1): 102-109. 